\title{
Congratulations to the A.O.U.
}

on its 7 yth Stated Meeting, Regina, August 25-30, 1959

by the Honourable A. G. Kuziak, Minister of Natural Resources, Govt. of Saskatchewan

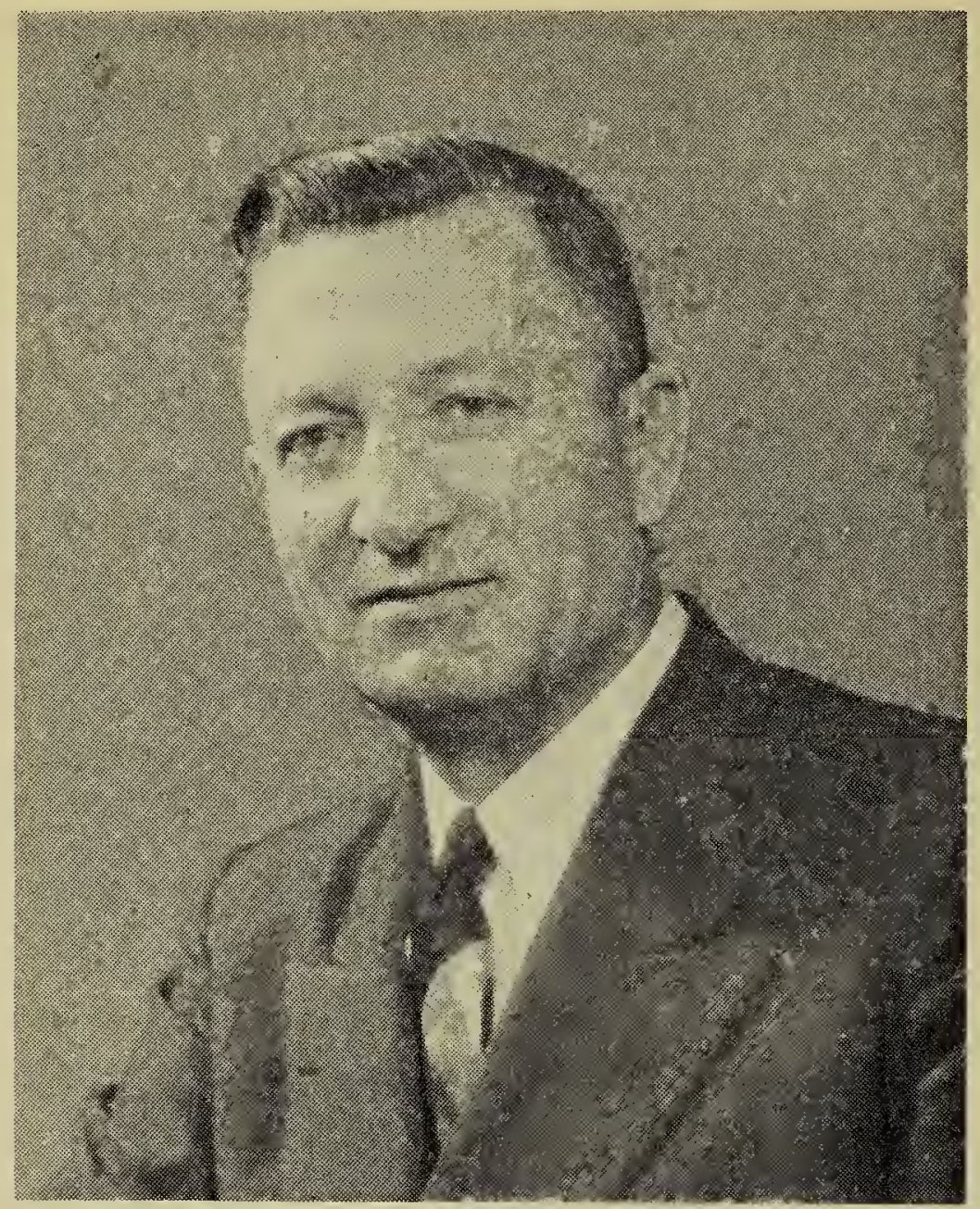

The Honourable A. G. Kuziak

I am very pleased to have this opportunity to extend a welcome to the members and guests of the American Ornithologists' Union on behalf of the Government of Saskatchewan and particularly on behalf of the Saskatchewan Museum of Natural History, which is a part of my Department of Natural Resources.

We in Saskatchewan consider it an honour that you have selected our province as the location for your 77 th Stated Meeting. Furthermore, we consider it a tribute to the many people of our province who have contributed down through the years to the observation and scientific study of bird life. The enthusiastic response of the people to my department's Museum of Natural History and to other undertakings such as the Blue Jay - the journal of the Saskatchewan Natural History Society-are indications of the tremendous interest in nature that exists in this part of Canada.

I hope you will pardon my prejudice if I say that you could not have selected a more appropriate setting for your annual meeting, not only because of the interest of our people but because of the richness of our bird life. I can only hope that the sandhill cranes, geese, ducks, and other birds which are displayed in our museum will appear for you on your field trips to provide a suitable climax for your meeting.

To me, this gathering of people from all walks of life and from all parts of North America is a welcome note in a world more and more given to political strife and to the worship of man-made structures. I am thankful for organizations such as the A.O.U. which are dedicated to the awakening of interest in, and the scientific study of nature.

I hope that your meeting here will stimulate further interest in the study of nature. And I hope that you, like the migratory biras that cross our borders each spring and fall, will enjoy your stay and return again many times to Saskatchewan. 